\title{
Methyl Chloride
}

National Cancer Institute

\section{Source}

National Cancer Institute. Methyl Chloride. NCI Thesaurus. Code C77476.

A colorless, flammable, toxic gas that was used widely as a refrigerant and has many current industrial applications, including use as a local anesthetic, a chemical intermediate in silicone polymer production and drug manufacturing, an extractant for oils and resins, a solvent in butyl rubber and petroleum refining, a propellant in polystyrene foam production, a methylating and chlorinating agent in organic chemistry and an herbicide. Exposure to methyl chloride can cause a wide variety of issues from frostbite, drowsiness and dizziness to paralysis, seizures and coma depending on the route and level (concentration and duration) of exposure. 